\section{Lockdlown and our national supply of blood products}

To the Editor: Our generation finds itself in an unprecedented situation, as coronavirus disease 2019 (COVID-19) causes widespread changes to everyone's lives. Our healthcare system has faced adversity in various forms, but this current crisis brings new and more difficult challenges.

An important aspect of medical treatment is the use of blood products. The availability of these products is reliant on voluntary donations and appropriate use by clinicians. A large proportion of donations are made from the elderly, perhaps at greatest risk from COVID-19, and educational institutions, now closed through isolation polices. Data from other countries highlight social distancing and self-isolation as important steps in slowing down transmission of coronavirus. ${ }^{[1]}$ However, these measures will drastically reduce the number of blood donations, unless different collection strategies are employed.

South Africa already has limited blood products, with the South African National Blood Service (SANBS) and Western Cape Blood Service (WCBS) needing to collect more than 3500 units of blood every day to maintain adequate stocks. Less than $1 \%$ of the population regularly donate blood, and more than $30 \%$ of donors are under 25 years of age, demonstrating the burden on blood collection when schools and universities are closed. The high incidence of HIV, trauma and chronic illness places tremendous demand on an already limited supply, with several areas still having limited access to blood products all these problems will persist during the COVID-19 pandemic.

There are ongoing efforts to improve appropriate and responsible use of these limited and life-saving blood products through patient blood management (PBM) systems. There is now an even greater need to implement and support these efforts. ${ }^{[2]}$ In the light of current events, we can expect a dramatic decrease in the number of donations, and subsequently a mismatch in supply and demand. The blood products available for our hospitals and clinics will therefore rapidly decrease. This will continue for months, and we consider that the following are important:

- Healthcare professionals should be aware of this pending problem and implement PBM programmes, ensuring that blood products are only used when necessary, through diagnosis and management of anaemia, of which the most common and treatable pre-operative cause remains iron deficiency. ${ }^{[2]}$

- Patients should generally only be transfused if alternative measures have failed and they are symptomatic from anaemia, or in cases of emergency. Single-unit transfusions should be used as far as possible. Healthcare workers should be made aware of transfusion threshold data showing that very few patients require blood transfusions if their haemoglobin concentration is $>7 \mathrm{~g} / \mathrm{dL}^{[3-5]}$ Hospital managers and transfusion committees must take proactive roles in directing PBM activities in their hospitals.
- The public should be made aware of this problem and make concerted efforts to donate blood out of their normal routine.

- The blood transfusion services should be supported by the Department of Health and public forums to ensure continued supply of products.

Addressing these issues will ensure that lives are saved and appropriate care delivered in these difficult times. Failure to address these issues timeously will result in a blood product supply crisis in which patients will suffer with increased mortality.

\section{R D Wise}

Discipline of Anaesthesiology and Critical Care, School of Clinical Medicine, University of KwaZulu-Natal, Durban, South Africa; and Adult Intensive Care Unit, John Radcliffe Hospital, Oxford University Hospitals Trust, Oxford, UK

robwiseicu@gmail.com

\section{W Gibbs}

Department of Anaesthesiology and Perioperative Medicine, Groote Schuur Hospital and Faculty of Health Sciences, University of Cape Town, South Africa

\section{J Louw}

Division of Clinical Haematology, Department of Medicine, Faculty of Health Sciences, University of Cape Town, South Africa

Author contributions. All authors contributed equally to the writing of this letter.

Funding. None.

Conflicts of interest. RDW has provided training on behalf of the SANBS MWG declares no conflicts of interest. VJL has received honoraria and/ or travel support and/or grant funding from the following: Acino, Austell, Novartis Oncology, Pharmacosmos, Takeda. VJL serves as non-executive director on the Board of the WCBS.

1. Jefferson T, Mar CBD, Dooley L, et al. Physical interventions to interrupt or reduce the spread of respiratory viruses. Cochrane Database Syst Rev 2011, Issue 7. Art. No.: CD006207. https://doi. org/10.1002/14651858.CD006207.pub4

2. Thomson J, Hofmann A, Barrett CA, et al. Patient blood management: A solution for South Africa. S Afr Med J 2019;109(7):471-476. https://doi.org/10.7196/SAMJ.2019.v109i7.13859

3. Shehata N, Mistry N, da Costa B, et al. Restrictive compared with liberal red cell transfusion strategies in cardic surgery: A meta-analysis. Fur Heart J 2019:40(13):1081-1088 https.//doiorg/10.1093/ in cardiac surger:

4. Holst L, Petersen M, Haase N, et al. Restrictive versus liberal transfusion strategy for red blood cell transfusion: Systematic review of randomised trials with meta-analysis and trial sequential analysis. BMJ 2015;350:h1354. https://doi.org/10.1136/bmj.h1354

5. Cable CA, Razavi SA, Roback JD, et al. RBC transfusion strategies in the ICU: A concise review. Crit Care Med 2019;47(11):1637-1644. https://doi.org/10.1097/CCM.0000000000003985

S Afr Med J 2020;110(5):337. https://doi.org/10.7196/SAMJ.2020.v110i5.14749 